Journal of Sustainable Development of Transport and Logistics

journal home page: https://jsdtl.sciview.net

Gambetta, R., \& Barić, D. (2020). Mobility market transformation - how mobility as a

service based on open source principles will impact the ecosystem. Journal of Sustainable

Development of Transport and Logistics, 5(2), 22-28. doi:10.14254/jsdtl.2020.5-2.2.

\title{
Mobility market transformation - how mobility as a service based on open source principles will impact the ecosystem
}

\author{
Ralph Gambetta *, Danijela Barić **(D) \\ ${ }^{*}$ Calypso Networks Association, \\ Rue Royale 76, B-1000 Brussels, Belgium \\ secretary@calypsonet-asso.org \\ ${ }^{* *}$ Faculty of Transport and Traffic Sciences, University of Zagreb, \\ Vukelićeva 4, HR-10000 Zagreb, Croatia \\ danijela.baric@fpz.unizg.hr
}

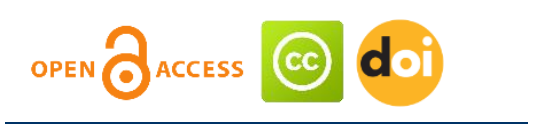

Article history:

Received: May 31, 2020

1st Revision: August 25, 2020

Accepted: November 04, 2020

DOI:

10.14254/jsdtl.2020.5-2.2

\begin{abstract}
Following the growing world population and associated need for increased transportation, there is a growing interest in some aspects of transport such as sustainability, to reduce $\mathrm{CO}_{2}$ emissions and reach climate objectives. Modern urban living is rapidly changing with new technological innovations, one of which is the possibility to integrate different electronic "on demand" services into one single medium. Public transport users need innovative, multi-applicative, multifunctional, safe and secure ticketing systems, easy to use. Concept of Mobility as a Service (MaaS) as an integration of various forms of transport services into a single mobility service accessible on demand is a new way of thinking about public transport. This paper focuses on mobility market transformation with main question how Mobility as a Service based on open source principles will impact the ecosystem.
\end{abstract}

Keywords: MaaS, public transport, open source, digitalisation, ticketing.

\section{Introduction}

Today a change of the mobility paradigm can be witnessed on a global scale. The transport sector is targeted by very large and intrusive players such as Uber, Lyft, Google, etc. and captured by other very small players, start-ups, which offer solutions that are often ephemeral and just as challenging for transport authorities. At the same time, the above-mentioned actors and solutions mark an unprecedented trend towards digitalization in urban areas, not only in public transport, but in all other relevant sectors such as commerce, education, parking, banking, payments. They all become connected among themselves and with the customers in a complex ecosystem also known as "smart city". On one side, such evolutions represent an opportunity for public transport authorities: the diversity of available and future digital solutions can support the development of innovative

Corresponding author: Danijela Barić

E-mail: danijela.baric@fpz.unizg.hr 
products and services that meet all stakeholder needs once the organizing authorities ensure the superimposition of legal frameworks and operational and business rules.

On the other side, the digitalization trend triggers challenging governance opportunities as most of the solutions are provided by private actors. Seen the long history and the patronage public transport has in Europe it is important for transport operators and authorities to maintain control of their systems. Public transport companies are a value for the cities and regions that has been created and enforced over the last decades. Disruptive approaches as we currently see them appear in the US, are a challenge for the traditional European transport eco system. Naturally, we have to provide the relevant advances in terms of technology to the public transport sector by matching the best of each sector including ITS, investment and business under the aligned set of Communitarian rules and regulations. Even more the sovereignty of the digital world is at stake for the authorities. The provision of big data needs to become a value for the cities and regions allowing impacting significantly the set objectives in terms of congestion and emission reduction. Achieving the green goals on a European level will mean to give a minimum of control and management of the future eco system to regions and cities. In this respect, the adoption of open standards and APIs allows to set the rules of fair play and equal conditions among the involved stakeholders. Accessibility has to granted as technology offerings are ready and deployed in various EU cities and costumers have access to mobile devices and to mobile payments solutions. Both are fundamentals to enhance the increase of adoption of Mobility as a service (MaaS) concept and favor developments related to smart cities.

\section{Literature review}

MaaS is a still a very young concept, and the amount of MaaS-focused research is rapidly increasing, which is also visible in scientific publications, the amount of which has increased strongly in 2017 and 2018. The early scientific findings related to Mobility as a Service, and the wider scale impacts on mobility and transport system of MaaS, according to (EMTA) are:

- MaaS makes the transport system more efficient and helps to recognize and choose the daily mobility options

- Personalized services enable seamless trip chains by integrating different transport modes

- Popularity of private cars is expected to reduce as flexible choices such as car-sharing and on-demand ride-sharing services become more common. Overall, MaaS seems to increase use of sustainable transport modes

- Sustainable transport modes are expected to become more popular albeit there is not much discussion of the role of cycling in the MaaS literature.

- New flexible transport modes force conventional public transport to adapt to a more service-oriented system

- MaaS trials enable great possibilities to get to know and try out new mobility services

- Public sector has a key role as an enabler of MaaS e.g. by supportive Legislation

According to Hensher (2017) some examples of recent implementation and/or planning for MaaS schemes in a number of countries are MOBIB in Brussels, HANNOVERmobil, EMMA in Montpellier, SMILE7 in Vienna, Moovel in Germany, etc.

The popularity of MaaS has spread to become a global phenomenon which is research from various angels. Some of the papers are based on survey research. Matyas, M., \& Kamargianni, M. (2019) present in their paper the design of a survey including a stated preference experiment that captures the complex decision-making process of purchasing MaaS products. Respondents are presented with repeated choices between four hypothetical MaaS plans out of which three are fixed plans and one is a menu option. This approach allows for testing people's preferences and willingness to pay for flexibility. The attributes of the plans include transport modes and amounts, mode specific features (e.g. 10-min taxi guarantee), transferability (meaning how much of left over mode-attributes can be transferred to the next month), special bonuses (e.g. a free dinner for two) and the price of the plan. The stated preference is tested with a number of focus groups.

The paper (Matyas, 2020) aims to identify potential ways that MaaS (specifically MaaS plans) could help encourage behavioural change; and understand the barriers to using alternative transport modes. In-depth interviews and qualitative analysis are applied to the case study of London. The 
results indicate that individuals segment the transport modes offered via MaaS into three categories: essential, considered and excluded.

With the development of MaaS emerging technologies such as mobile data mining gives some new solutions for optimizing bike-sharing system and predicting the emission reduction. Zhang et al (2018) propose a bike-sharing layout optimization and emission reduction potential analysis structure under the concept of MaaS. A human travel mode detection method and a geometry-based probability model are proposed to support particle swarm optimization process. Authors implement a comparison study to analyze the computational efficiency in Tokyo as the study case with about 3 million GPS trajectories. The result shows that with the increase of station number from 30 to 90, the adoption of bike-sharing system can reduce about 3.1-3.8 thousand tonnes of CO2 emission.

\section{Mobility as a Service and open source ticketing}

The term Mobility as a Service (MaaS) was coined in Finland in 2014. Then defined as 'a system, in which a comprehensive range of mobility services are provided to customers by mobility operators', MaaS has more recently been described as an integrative concept that bundles different transport modalities into joint, seamless service offerings, in order to provide tailored mobility solutions that cater for users' travel needs (MaaS alliance). Mobility as a Service framework is shown on Figure 1.

\section{Figure 1: Mobility as a Service Framework}

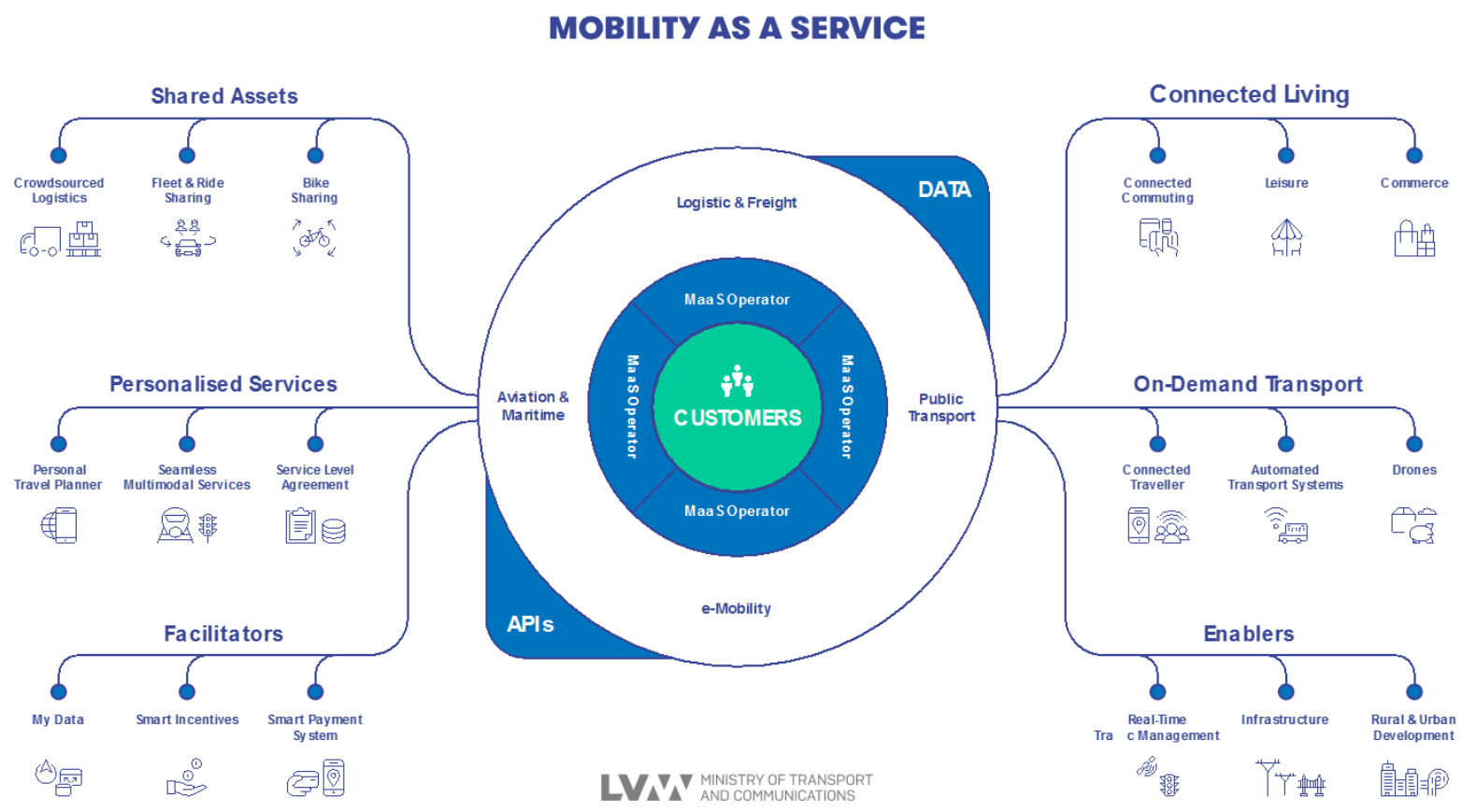

Source: MaaS Alliance (2017). White Paper Guidelines \& Recommendations to create the foundations for a thriving MaaS Ecosystem, available at https://maas-alliance.eu/wpcontent/uploads/sites/7/2017/09/MaaS-WhitePaper_final_040917-2.pdf

Mobility as a Service (MaaS) represents a new way of thinking about transport. It has the potential to be the most significant innovation in transport since the advent of the automobile. MaaS is the integration of various forms of transport services into a single mobility service accessible on demand. To meet a customer's request, a MaaS operator facilitates a diverse menu of transport options, be they public transport, ride- sharing, car- sharing or bike-sharing, taxi or car rental/lease, or a combination thereof. For the user, MaaS can offer added value through use of a single application to provide access to mobility, with a single payment channel instead of multiple ticketing and payment operations (Figure 2). For its users, MaaS should be the best value proposition, by helping them meet their mobility needs and solve the inconvenient parts of individual journeys as well as the entire system of mobility services (Smith, G. et al, 2018). 
A successful MaaS service also brings new business models and ways to organise and operate the various transport options, with advantages for transport operators including access to improved user and demand information and new opportunities to serve unmet demand. The aim of MaaS is to provide an alternative to the use of the private car that may be as convenient, more sustainable, help to reduce congestion and constraints in transport capacity, and can be even cheaper (MaaS alliance).

Whilst ticketing was initially a mere fare collection tool, it is now considered as an essential enabler of MaaS. The emergence of the MaaS concept has enabled the integration of many new mobility services such as car sharing, bicycle-sharing, car parks, taxis, ride hail services and carpooling with traditional public transport. To get from A to B, travellers have several mobility options, connected to one another, with an open choice of alternatives according to preferences, with multimodal information available at any place and at any time, with easy and unconstrained access and connection from one service to another. Provided it is both accessible and open, contactless ticketing can accelerate the implementation of MaaS, as it offers concrete solutions to facilitate access to all forms of mobility by integrating sustainable development concerns and by influencing modal balance. MaaS has given back to ticketing a major role as the gateway to mobility for all, after having often been wrongly perceived as just a means of paying for transport (Calypso Networks Association, 2019).

Figure 2.:Whim application for MaaS in Helsinki

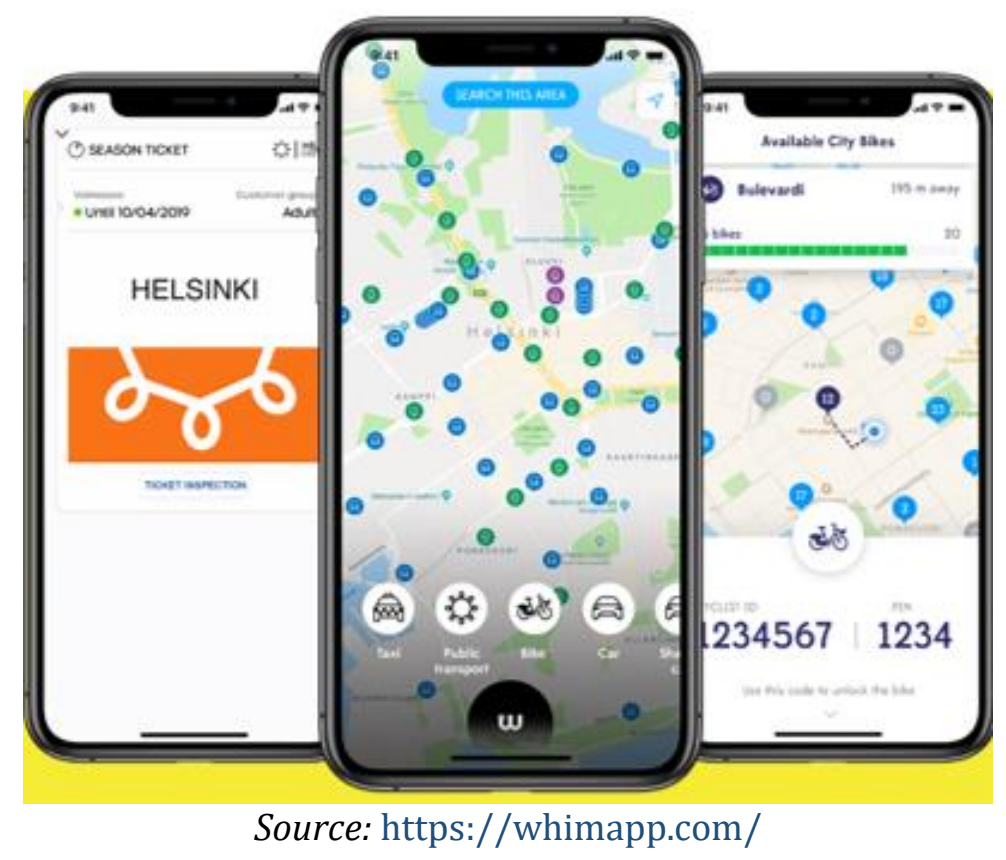

Concerning the ticketing, for the MaaS the ecosystem must be based on standards, APIs and open technologies as much as possible. This opening has been a reality for several years in the field of passenger information services and has given rise to a wealth of attractive applications, thanks in particular to open data. To allow ticketing to follow that path of opening initiatives, Calypso Networks Association has provided the first fully open source ticketing API free of charge Eclipse - Keyple. Keyple offers a concrete and operational answer to two key issues: mastering ticketing systems and providing a simple and fast access to Calypso technology, especially as part of MaaS schemes. Keyple SDK can be extended at any level: above the Universal SE Interface, at generic commands' set layer, or higher, to add Calypso processing, or to manage other kinds of SE solutions (Figure 3). It will become easier to develop connected and interoperable services combining all forms of mobility: metro, train, tramways, buses, park \& rides, bike-sharing, car-sharing, car-pooling, e-scooter-sharing, etc. Keyple aims at accelerating the integration and development of high-performance ticketing applications. It will enable mobility stakeholders, event organisers, sports, cultural and leisure infrastructure managers to easily and economically implement ticketing systems based on a common, open and modular platform, whilst keeping Calypso's fundamental characteristics of reliability, security and interoperability (Gambetta \& Barić, 2019). 
Figure 3: Keyple solution

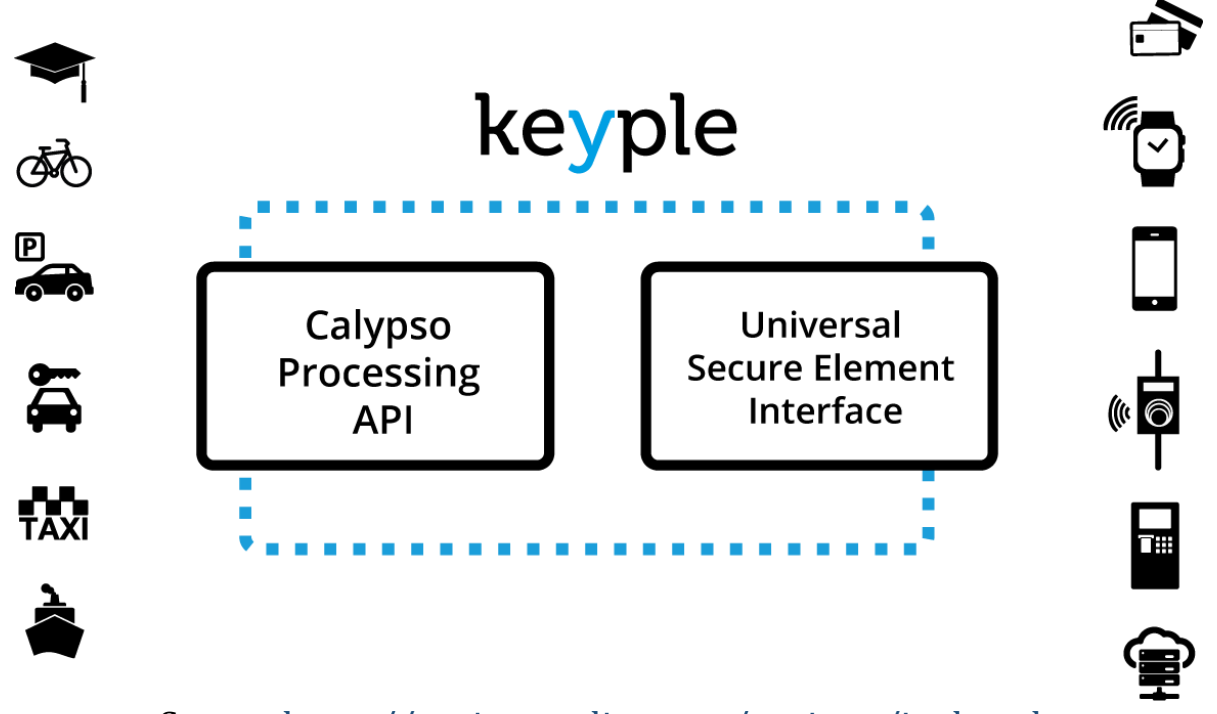

Source: https://projects.eclipse.org/projects/iot.keyple

\section{Discussion}

Emerging new technologies are strongly linked to the appearance of digital platforms that allow new forms of management of services. Examples like Uber and Flixmobility have shown how two very strong platforms that have impacted largely the mobility systems in Europe and the life of users. The availability of such new digital platform allows a new form mobility related service. These services could be e.g. on an intermediate level between taxi and bus. Personalization of such services coupled with an increase of flexibility on the management side shall provide benefits to all actors involved including the public transport companies. Creating cost benefits by introducing the sharing economy principles to this kind of public service obligations will also provide more security to its users and have societal impact in terms of decreasing of private cars, thus contributing to climate change mitigation. With such innovative service models, the arrival of autonomous vehicles can be anticipated by the proper use and development of public policies in the related sector. Furthermore, it will allow the public assets to increase their related know how and prepare for the correct use of big data being in line with the set European GDPR policies.

Successful adoption of technology is one of the key elements to sustainable economic development and growth. In addition, intelligent solutions are a driving force to modernise society. With urban transport at the core of future mobility patterns we see the need of intelligent solutions that will allow users to benefit from integrated services. Only by becoming part of lifestyle services public transport will create the necessary positive image and allow increased ridership on the long term. Customers want to be informed about the services they use and everything that relates to them. Matching these expectations means that numerous services need to be integrated with smart ticketing such as real-time information, guidance, events information etc. Internet 2.0 has started to educate users to perceive their environment this way and urban transport needs to adapt to this new societal paradigm.

Calypso technology has contributed to many significant developments in the frame of smart ticketing. To manage successfully the upcoming mobility challenges the ability to offer a standardized and interoperable transport application, matching the needs of transport operators irrespective of what customer medium they run on, is essential. To better enhance developments the technical specification has been opened. By matching the philosophy of open source to ticketing a new dimension within the world of developers has been reached. Only by having open APIs and ticketing specifications it will be possible to act as a connector for mobility services. The availability and accessibility of technology through "Open Sources" means a significant broadening of the perimeter of the potential technology deployment and it widens in parallel the current eco system to meet the future challenges of mobility by guaranteeing a high level of security of transactions. To be prepared to the new challenges of ticketing, the Calypso community has initiated one year ago this path towards 
Open Source. This means that over the coming years a switch to a model oriented on the parameters of an Open Source approaches will be made. Consequently, a significant broadening of the perimeter of technology will open to new business models. With higher service orientation, the competitiveness of Calypso will increase the value for its users and generate new streams of revenue. The Open Source SDK that will be provided by CAN, the association managing the Calypso technology) through the Open Source Platform ECCLIPSE will allow local suppliers to implement Calypso ticketing systems without having to be linked to big traditional ticketing integrators. This strategy will allow the creation of local added value and work force by integrating every player of the ticketing eco system without any discrimination.

\section{Conclusions}

Beyond its original function of collecting revenues from transport, ticketing is now considered as the backbone of Mobility as a Service (MaaS). Ticketing must enable mobility services to be combined and offer passengers a seamless, end-to-end, easily accessible transport offer. As the ticketing system typically lasts for up to 20 years, its implementation represents an important investment. Therefore, ticketing system must enable evolutions and upgrades throughout its life. Whilst ticketing was initially a mere fare collection tool, it is now considered as an essential enabler of MaaS which has given back to ticketing a major role as the gateway to mobility for all, after having often been wrongly perceived as just a means of paying for transport. Sustainable door-to-door mobility need innovative mobility solutions complement with traditional public transport and useful transport services. This has driven the need to connect public transport services together to provide a coherent mobility offer, which is the principle that guides the concept of Mobility as a Service. In conclusion, ticketing based on open source principles is the key to the making mobility services work together, as it should facilitate the transition from one form of mobility to another seamlessly and contribute to the attractiveness of services through an adapted fare offer.

\section{Citation information}

Gambetta, R., \& Barić, D. (2020). Mobility market transformation - how mobility as a service based on open source principles will impact the ecosystem. Journal of Sustainable Development of Transport and Logistics, 5(2), 22-28. doi:10.14254/jsdtl.2020.5-2.2

\section{References}

Calypso Networks Association (2019). Ticketing for MaaS, best practices for durable systems.

EMTA (2008). Study on electronic ticketing in public transport, Final Report.

Gambetta, R. \& Barić, D. (2019) Open Source Ticketing Enhancing Mobility as a Service Schemes, 7th International Conference "Towards a Humane City".

Hensher, D. A. (2017). Future bus transport contracts under a mobility as a service (MaaS) regime in the digital age: Are they likely to change?, Transp. Res. Part A Policy and Practice, 98, 86-96.

MaaS Alliance (2017). White Paper Guidelines \& Recommendations to create the foundations for a thriving MaaS Ecosystem, available at https://maas-alliance.eu/wpcontent/uploads/sites/7/2017/09/MaaS-WhitePaper_final_040917-2.pdf.

Malliance.
$\quad$ content/uploads/sites/7/2018/03/ERT_MaaS_leaflet_FINAL.pdf.

Matyas, M. (2020). Opportunities and barriers to multimodal cities: lessons learned from in-depth interviews about attitudes towards mobility as a service. Eur. Transp. Res. Rev. 12(7) https://doi.org/10.1186/s12544-020-0395-z.

Matyas, M., \& Kamargianni, M. (2019). Survey design for exploring demand for Mobility as a Service plans. Transportation, 46, 1525-1558 https://doi.org/10.1007/s11116-018-9938-8. 
Smith, G., Sochorad, J., \& Karlsson, M. (2018). Mobility as a service: Comparing developments in Sweden and Finland, Research in Transportation Business \& Management, 27, 36-45.

Zhang, H. et al. (2018). MaaS in Bike-Sharing: Smart Phone GPS Data Based Layout Optimization and Emission Reduction Potential Analysis. Energy Procedia, 152, 649-654.

Journal of Sustainable Development of Transport and Logistics (ISSN: 2520-2979) is published by Scientific Publishing House "CSR", Poland, EU and Scientific Publishing House "SciView", Poland, EU

Publishing with JSDTL ensures:

- Immediate, universal access to your article on publication

- High visibility and discoverability via the JSDTL website

- Rapid publication

- Guaranteed legacy preservation of your article

- Discounts and waivers for authors in developing regions

Submit your manuscript to a JSDTL at https://jsdtl.sciview.net/ or submit.jsdtI@sciview.net 